\title{
The laboratory diagnosis of HIV infections
}

\author{
Margaret Fearon MD FRCPC
}

M Fearon. The laboratory diagnosis of HIV infections. Can J Infect Dis Med Microbiol 2005;16(1):26-30.

HIV diagnostic testing has come a long way since its inception in the early 1980s. Current enzyme immunoassays are sensitive enough to detect antibody as early as one to two weeks after infection. A variety of other assays are essential to confirm positive antibody screens (Western blot, polymerase chain reaction [PCR]), provide an adjunct to antibody testing (p24 antigen, PCR), or provide additional information for the clinician treating HIV-positive patients (qualitative and quantitative PCR, and genotyping). Most diagnostic laboratories have complex testing algorithms to ensure accuracy of results and optimal use of laboratory resources. The choice of assays is guided by the initial screening results and the clinical information provided by the physician; both are integral to the laboratory's ability to provide an accurate laboratory diagnosis. Laboratories should also provide specific information on specimen collection, storage and transport so that specimen integrity is not compromised, thereby preserving the accuracy of laboratory results. Point of Care tests have become increasingly popular in the United States and some places in Canada over the past several years. These tests provide rapid, on-site HIV results in a format that is relatively easy for clinic staff to perform. However, the performance of these tests requires adherence to good laboratory quality control practices, as well as the backup of a licensed diagnostic laboratory to provide confirmation and resolution of positive or indeterminate results. Laboratory quality assurance programs and the participation in HIV proficiency testing programs are essential to ensure that diagnostic laboratories provide accurate, timely and clinically relevant laboratory results.

Key Words: HIV antibody test; HIV diagnosis; HIV testing algorithm; HIV testing and quality assurance; Polymerase chain reaction (PCR)

$\mathrm{H}^{\mathrm{i}}$ wer IV infection is identified either by the detection of HIV-specific antibodies in serum or plasma or by demonstrating the presence of the virus by nucleic acid detection using polymerase chain reaction (PCR), p24 antigen testing or, rarely these days, by growing virus in cell culture. Antibody testing is the method most commonly used to diagnose HIV infection. With the highly sensitive HIV-1/ HIV-2 enzyme immunoassay (EIA) tests currently on the market, seroconversion can be detected within two to three weeks of infection in the majority of cases. In a small number of early seroconverters who are still in the 'window period', the p24 antigen may become positive before antibody is detectable. Therefore, to enable the laboratory to select

\section{Le diagnostic des infections au VIH}

Les tests diagnostiques du VIH ont beaucoup évolué depuis leur implantation au début des années 1980. Les dosages immunologiques enzymatiques actuels sont assez sensibles pour déceler des anticorps dès une ou deux semaines après l'infection. Divers autres dosages sont essentiels pour confirmer des dépistages d'anticorps positifs (transfert Western, réaction en chaîne de la polymérase [PCR]), s'ajouter aux épreuves d'anticorps (antigène p24, PCR) ou fournir de l'information supplémentaire au clinicien qui traite des personnes séropositives au VIH (PCR qualitative et quantitative et génotypage). La plupart des laboratoires diagnostiques possèdent des algorithmes d'épreuve complexes afin de garantir l'exactitude des résultats et l'usage optimal des ressources de laboratoire. Le choix des dosages est orienté par les résultats initiaux du dépistage et par l'information clinique fournie par le médecin. Ces deux facteurs contribuent à la capacité du laboratoire de fournir un diagnostic de laboratoire précis. Les laboratoires devraient également fournir de l'information précise sur le prélèvement, l'entreposage et le transport des échantillons, afin que leur intégrité ne soit pas compromise et que l'exactitude des résultats de laboratoire soit préservée. Depuis quelques années, les épreuves au point d'intervention gagnent en popularité aux États-Unis et dans certaines régions du Canada. Ces tests fournissent des résultats rapides sur place, sous une forme relativement facile à exécuter pour le personnel clinique. Cependant, l'exécution de ces tests exige l'adhésion à de bonnes pratiques de contrôle de la qualité en laboratoire ainsi que l'apport d'un laboratoire diagnostique autorisé afin de confirmer les résultats positifs et de résoudre les résultats indéterminés. Les programmes d'assurance-qualité des laboratoires et la participation à des programmes de tests de vérification des compétences du VIH sont essentiels pour s'assurer que les laboratoires diagnostiques fournissent des résultats précis, rapides et pertinents d'un point de vue clinique.

appropriate testing, it is important to provide a clinical history that includes any recent high-risk behaviour or symptoms consistent with seroconversion illness (1-3).

All HIV diagnostic laboratories should confirm repeatedly positive EIA screen tests with another assay (Figure 1). The Western blot - the most commonly used confirmatory test - is a highly specific immunoblot that allows for the visualization of antibodies to the structural polypeptides of HIV. Some laboratories may use a radioimmunoprecipitation assay as their confirmatory assay or as part of their HIV testing algorithm. In a radioimmunoprecipitation assay test, radiolabelled viral proteins are reacted with the patient's serum to produce radioactive antigen-antibody complexes. 


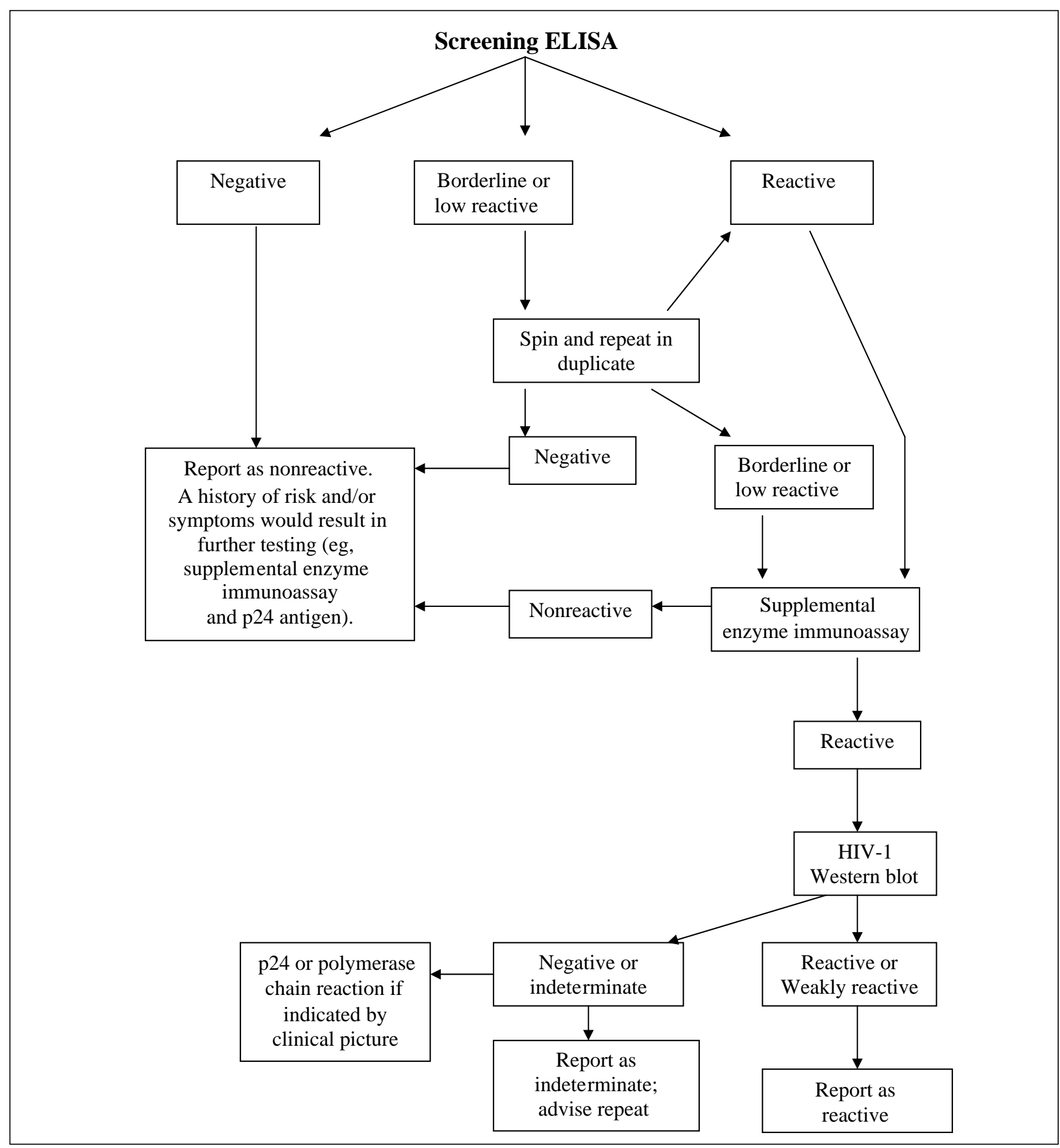

Figure 1) Sample HIV laboratory testing algorithm and flow chart

In cases where antibody testing may be insufficient to determine whether a patient is infected, it is necessary to perform DNA PCR, a nucleic acid amplification method that allows for the detection of viral DNA integrated into the host cell's genomic DNA (Figure 1). PCR is particularly useful in testing infants of HIV-positive mothers; these infants may carry maternal antibody to 15 months of age (4). It is also useful when testing patients who are agammaglobulinemic or in rare cases where patients appear to have symptoms of advanced HIV infection but do not demonstrate HIV-specific antibodies.

Aside from diagnostic HIV testing, laboratories may also offer quantitative PCR (RNA) testing (viral load), which is used to help determine the initiation of drug therapy and monitor the effectiveness of therapy. HIV genotyping is a newer adjunct to patient management and is used to assist in 
tracking the development of drug resistance and guide the modification of antiretroviral drug selection (3).

\section{HIV-2}

Most laboratories use an HIV-1/HIV-2 screening assay which will pick up the relatively small number of HIV-2-infected individuals seen in Canada. Strongly positive screen test samples, which give an indeterminate or unusual HIV-1 Western blot pattern, are retested on a specific HIV-2 blot.

\section{SPECIMEN CHOICE, COLLECTION AND TRANSPORT}

For standard HIV-1/HIV-2 antibody testing, including p24 antigen and all confirmatory testing, a single tube $(10 \mathrm{~mL})$ of clotted whole blood is sufficient. If possible, a dedicated tube for HIV testing is preferred to minimize the possibility of cross contamination during handling. Most assays currently in use are validated for use on serum, including serum collected in serum separator tubes and plasma collected in EDTA, sodium heparin, sodium citrate, acid-citrate-dextrose, cell preparation tube or potassium oxalate. Laboratories should provide their clients with specific guidelines on the collection and submission of samples for HIV testing locally. Performance of these assays, including p24 antigen testing, has been validated on serum and plasma. The assays have not been validated on postmortem specimens or body fluids such as urine, saliva, semen or pleural fluid.

A number of tests designed specifically for urine, oral fluid or finger-prick specimens are in use for testing in special circumstances (eg, insurance screening, population surveillance). These tests are mainly used in epidemiological studies or in point-of-care (POC) testing to provide rapid preliminary results. Specimens are collected as indicated by the manufacturer. Aside from providing rapid results, these tests offer the following advantages: decreased infectious hazard because no venipuncture is required; specimens can be collected in a nonclinical setting; and finally, certain specimens can also be used for other sexually transmitted infection testing $(2,5)$. It is imperative that positive results obtained with these tests are confirmed with a more conventional blood test performed by a licensed diagnostic laboratory.

Specimens requiring storage before shipping to the laboratory should be stored no longer than seven days, preferably at $4^{\circ} \mathrm{C}$, and no longer than three days at room temperature. For longer storage periods, the serum or plasma must be separated from the clot or cells and stored at $-20^{\circ} \mathrm{C}$. Any sample that has been previously frozen should be indicated as such because special handling may be required for some of the test kits currently in use. For shipping to the laboratory, specimens must be packaged and labelled in compliance with Transport Canada's Transportation of Dangerous Goods regulations (6) as they apply to the shipment of clinical specimens. Specimens may be shipped refrigerated $\left(2^{\circ} \mathrm{C}\right.$ to $\left.8^{\circ} \mathrm{C}\right)$, on wet ice or frozen (serum) at $-20^{\circ} \mathrm{C}$, and shipped on dry ice or at ambient temperatures not exceeding $26^{\circ} \mathrm{C}$. All clinical diagnostic specimens must be properly labelled with a patient identifier and accompanied by a completed laboratory requisition with relevant clinical information to guide appropriate test selection. Specimens that are unlabelled, improperly labelled or do not match the accompanying requisition should not be tested by the laboratory in most circumstances.
Laboratories must provide clients with guidelines for the collection, storage, shipping, timing and types of tubes used for PCR testing. These specimens generally need to be processed within $48 \mathrm{~h}$ of collection. Blood collection tubes may vary depending on the PCR assay being used. Generally, for qualitative PCR, a full $(7 \mathrm{~mL}$ ) acid-citrate-dextrose (yellow top) or EDTA (lavender top) vacutainer tube is required. Specimens should be stored and shipped at $2{ }^{\circ} \mathrm{C}$ to $25^{\circ} \mathrm{C}$ as soon as possible to the laboratory. Do not freeze! Processing to prepare the specimen for testing must take place within $48 \mathrm{~h}$ of collection. Viral DNA denatures over time and becomes undetectable.

For most quantitative viral RNA assays (viral load RNA PCR, branched DNA), $10 \mathrm{~mL}$ of whole blood in EDTA or $2 \times 7 \mathrm{~mL}$ of whole blood in plasma preparation tubes (PPT) or $5 \mathrm{~mL}$ of separated plasma (from EDTA or PPT) is required. Whole blood in EDTA is stable for only $4 \mathrm{~h}$, while blood in PPT, if centrifuged within $4 \mathrm{~h}$ of collection, is stable at room temperature for $24 \mathrm{~h}$. Plasma can be stored frozen for three months before testing, and is stable for $24 \mathrm{~h}$ at room temperature.

\section{DIAGNOSTIC TESTS}

Only Health Canada-approved tests should be used by diagnostic laboratories in Canada.

\section{HIV EIA}

EIA is commonly used as a screening assay for many infectious diseases, including HIV. These assays are used because they are highly sensitive and generally amenable to automation, facilitating high-volume testing. HIV EIAs have become increasingly more sensitive and specific since HIV testing began in the early 1980s. This has shortened the 'window period', or the time from exposure to seroconversion, from up to 12 weeks or more in the early days of diagnostic testing to the current 'window period' of less than three weeks in most cases.

The small disadvantage of such a highly sensitive test is that the test produces false positives, the number and type of which vary with the assay used and the HIV prevalence in the tested population. All HIV diagnostic laboratories must confirm repeated EIA screen-positive results by a confirmatory assay, usually with Western blot. Laboratories may choose to first test with a second EIA assay, which uses a different part of the viral antigen for antibody capture, as part of their testing algorithm. Specimens that screen positive in the first assay but negative in the second assay should still be considered for confirmatory testing if the patient is symptomatic or high risk.

\section{p24 antigen}

p24 antigen tests are also EIA-based and use antibody to capture the disrupted p24 antigen from patient serum. Positive results that are repeatable must be confirmed with a neutralization procedure. In rare instances, the p24 antigen can be detected before HIV antibody in newly infected individuals. This test is useful for specimens from patients that are high risk and symptomatic but HIV EIA-negative, or for specimens that are EIA-positive but Western blot-negative or -indeterminate (Figure 1). A follow-up HIV antibody test should be requested when a patient is p24 antigen-positive but antibody-negative. In a seroconverting patient, the follow-up specimen will be positive within a few weeks after the initial screen. It is 
important to remember that not all seroconverting patients will have detectable p24 antigen, and that this antigen may not be reliably found in individuals who are known to be HIV antibody-positive.

\section{Western blot}

The Western blot is an immunoblot that allows for the characterization of antibodies to each viral protein. Patient serum is reacted with a nitrocellulose strip containing all of the constitutive HIV virus proteins (core and envelope), arranged by molecular weight after polyacrylamide gel electrophoresis. Any specific antibodies present in the patient's serum will bind to the antigen, producing a coloured band when alkaline phosphataselabelled, antihuman immunoglobulin $\mathrm{G}$ conjugate and colour development solution are added. These bands can be visualized, and positivity is assessed following the manufacturer's recommendations and based on the number and type of bands present. Generally, a specimen must show a positive reaction with a minimum of one core band and one envelope band to be judged positive by Western blot.

Specimens that have bands present but do not fulfill the criteria for positivity are called Western blot indeterminate, and a follow-up specimen should be requested, usually collected three to four weeks after the initial specimen. In follow-up, patients will either show a definitive pattern indicating that they have seroconverted or will demonstrate the same banding pattern as previously observed. In the latter circumstance, the vast majority of these patients are HIV-negative and have nonspecific antibody. In these cases, if the patient is considered to be at risk or is particularly anxious, a qualitative PCR may be recommended to confirm that the patient is truly HIVnegative. Because these indeterminate banding patterns may be seen in patients who are not infected, the Western blot does not make a good screening test for HIV. The test is also much more labour intensive and costly than EIA tests and does not allow for the efficient processing of large numbers of specimens.

Specimens that have an unusual band pattern not reflective of EIA optical density values should either be tested on an HIV-2 blot or forwarded to the National Laboratory for HIV Reference Services (Ottawa, Ontario) for HIV-2 testing. Generally, HIV-2 positive specimens exhibit antibody to many HIV-specific bands but lack antibody to the envelope components of HIV-1.

\section{Qualitative PCR}

PCR is a method that amplifies viral nucleic acid to allow for its detection in patient specimens. It is a particularly specific and sensitive test which can pick up very small numbers of viral particles. PCR is very useful in the diagnosis of HIV infection in babies born to infected mothers. Babies will carry maternal antibody up to approximately 15 months of age and, therefore, the antibody test is not a reliable indicator of infection in these children.

Because of the very specific nature of the primers used in the HIV-1 DNA PCR assay, caution should be used in assessing a negative result in an infant if the mother is likely to have HIV-2 or a non-B HIV infection. It may be prudent to ensure that the HIV DNA PCR assay is effective in detecting the mother's HIV infection if there is any likelihood that the case is not an HIV subtype B infection. In North America, this would be a very uncommon finding.

PCR may also be useful in resolving indeterminate Western blot results and testing immunocompromised individuals who may not mount an antibody response.

\section{Quantitative RNA PCR and genotyping}

Quantitative RNA PCR must only be used to monitor HIV-positive individuals before or during antiretroviral therapy. It is used in conjunction with CD4 counts and general clinical assessments to ascertain when therapy should be started. It is also used to help determine the patient's response to therapy. Genotyping is used to monitor the development or presence of drug resistance in patients before or during therapy. It is also used to assist physicians in their choice of antiretroviral drug combinations for the patient $(3,7)$.

Quantitative PCR should not be used as a diagnostic test for HIV because false positives and false negatives can occur in these circumstances.

POC: POC testing is testing carried out wherever the patient is located - in a clinic, hospital or doctor's office. The use of such testing varies across Canada, with some provinces not using it at all and others using it extensively in sexually transmitted infection clinics or hospitals and as a preliminary screen for needlestick exposures in a health care setting (8). At an HIV consensus meeting in May of 2002 (9), a consensus statement was drawn up to address the use of POC tests. The basic recommendations are as follows:

- Only a Health Canada-approved device should be used.

- These tests should be used only in sites that provide a comprehensive quality assurance program as it relates to laboratory testing, as stated below.

- The devices should only be used in specific circumstances where immediate results are required, such as needlestick exposures and high-risk peripartum situations.

- All positive or difficult-to-interpret POC results must be confirmed by standard HIV serological testing. Negative results from someone likely to be in the 'window period' should also prompt full serological testing with repeat testing as required.

\section{PROFICIENCY AND QUALITY ASSURANCE}

\section{Proficiency testing}

Participation in proficiency testing is a key component of any laboratory quality assurance program, whether available locally, nationally or internationally (10). All HIV diagnostic laboratories in Canada should participate in the Health Canada HIV Serology Panel, sent out yearly from the National Laboratory for HIV Reference Services (Ottawa, Ontario). The Centers for Disease Control and Prevention also offers an HIV proficiency program, the Performance Evaluation Program: Testing for Human Immunodeficiency Virus Type 1 Infection. In Ontario, the Quality Management Program - Laboratory Services (QMP-LS) offers proficiency panels for HIV several times per year. When external proficiency programs are not available, groups of laboratories may set up their own proficiency testing program by sharing samples among themselves. At the time of writing, the aforementioned proficiency testing 
programs are available free of charge to participants (the only costs are reagents and staff time). QMP-LS charges out-of-province participants. Participation in proficiency testing programs is also a requirement for laboratory accreditation, which is now carried out or planned in most provinces.

\section{Quality assurance}

Every laboratory should have a quality assurance program in place to continuously assess and improve the processes integral to the production of laboratory results. This ensures that physicians receive accurate and timely laboratory information to guide patient management. All aspects of handling of patient specimens from their arrival in the laboratory to the reporting of results must be monitored, documented and subject to quality control procedures. Regular audits of laboratory procedures and reviews of incident reports should be carried out by senior staff and summarized for discussion with the laboratory director $(10,11)$.

An up-to-date, complete laboratory manual or manual of standard operating procedures is an important component of the quality assurance program. The manual should be

\section{REFERENCES}

1. Bartlett JG, Gallant JE. 2000-2001 Medical Management of HIV Infection. Baltimore: Port City Press, 2000.

2. Centers for Disease Control and Prevention. Revised guidelines for HIV counseling, testing, and referral. MMWR Recomm Rep 2001;50:1-57.

3. Zhang M, Versalovic J. HIV update. Diagnostic tests and markers of disease progression and response to therapy. Am J Clin Pathol 2002;118(Suppl):S26-32.

4. Division of STD Prevention and Control, Bureau of HIV/AIDS, STD and TB, Laboratory Centre for Disease Control, Health Protection Branch, Health Canada. Canadian STD Guidelines, 1998 edn. Ottawa: Health Canada, 1998.

5. Oelemann WM, Lowndes CM, Verissimo Da Costa GC, et al. Diagnostic detection of human immunodeficiency virus type 1 antibodies in urine: A Brazilian study. J Clin Microbiol 2002;40:881-5.

6. Transportation of Dangerous Goods Act, 1992. <http://www.tc.gc.ca/tdg/consult/actreview/menu.htm> (Version current at December 10, 2004). reviewed regularly by senior staff and the laboratory director, and all staff must read and be familiar with the procedures they are responsible for performing in the laboratory.

Reagent and equipment performance must be monitored over time to detect any changes in quality and integrity. Routine daily, weekly and monthly equipment maintenance must be carried out as per the manufacturer's instructions. Levy-Jennings plots should be performed on a regular basis and reviewed by a senior technologist for any aberrant values or shifts in control performance. In addition to controls provided by the manufacturer, laboratories should run their own well-characterized, in-house controls and/or external controls, which may be purchased commercially. Controls should be selected to include weak positives or borderline samples as well as those giving a strong positive and negative result on each assay used in the laboratory. On automated instruments, controls should be placed in a position to detect carry-over. Procedures to be followed when controls are out of range must be clearly described in the laboratory manual, and problems and corrective action should be documented by laboratory staff.

7. Hirsch MS, Brun-Vezinet F, Clotet B, et al. Antiretroviral drug resistance testing in adults infected with human immunodeficiency virus type 1: 2003 recommendations of an International AIDS Society-USA Panel. Clin Infect Dis 2003;37:113-28.

8. Johnston BL, Conly JM. Point-of-care testing for HIV: HIV counselling and testing. Can J Infect Dis 2002;13:85-8.

9. Kilby DL, Major CJ, Steben MH, Sutherland WD, Bally GA. Pointof-care HIV testing using simple/rapid HIV test kits: Guidance for health-care professionals. Can Commun Dis Rep 2000;26:49-59. Also available at <http://www.hc-sc.gc.ca/pphb-dgspsp/publicat/ ccdr-rmtc/00vol26/index.html > (Version current at December 10, 2004).

10. Using Proficiency Testing (PT) to Improve the Clinical Laboratory; Approved Guideline. NCCLS GP27-A, 1999.

11. Continuous Quality Improvement: Essential Management Approaches; Approved Guideline. NCCLS GP22-A, 1999. 


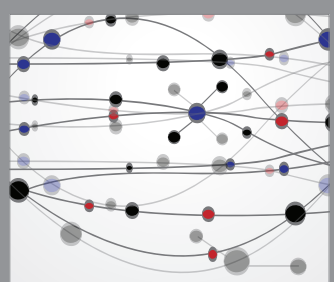

The Scientific World Journal
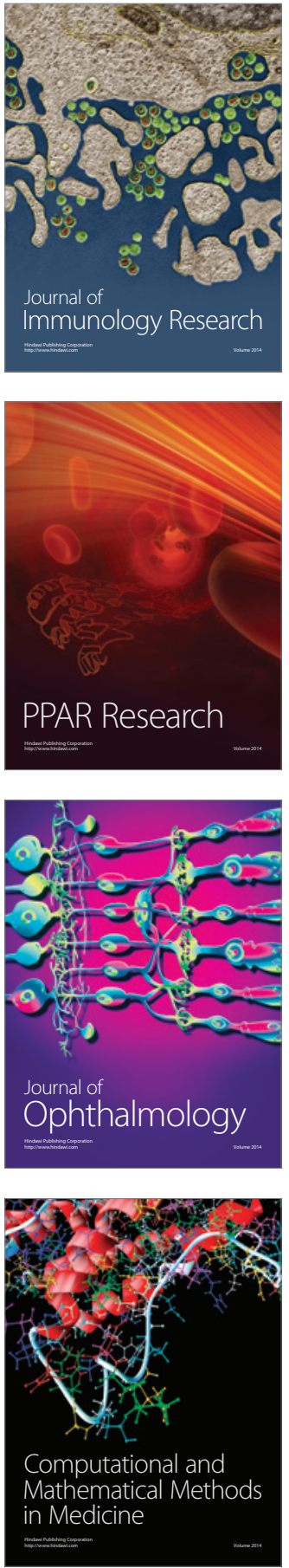

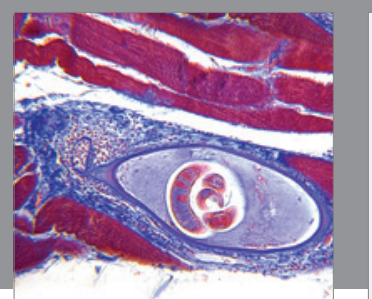

Gastroenterology Research and Practice

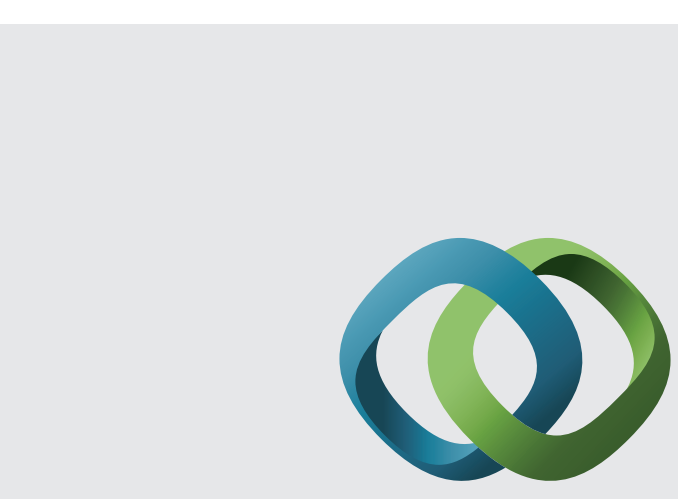

\section{Hindawi}

Submit your manuscripts at

http://www.hindawi.com
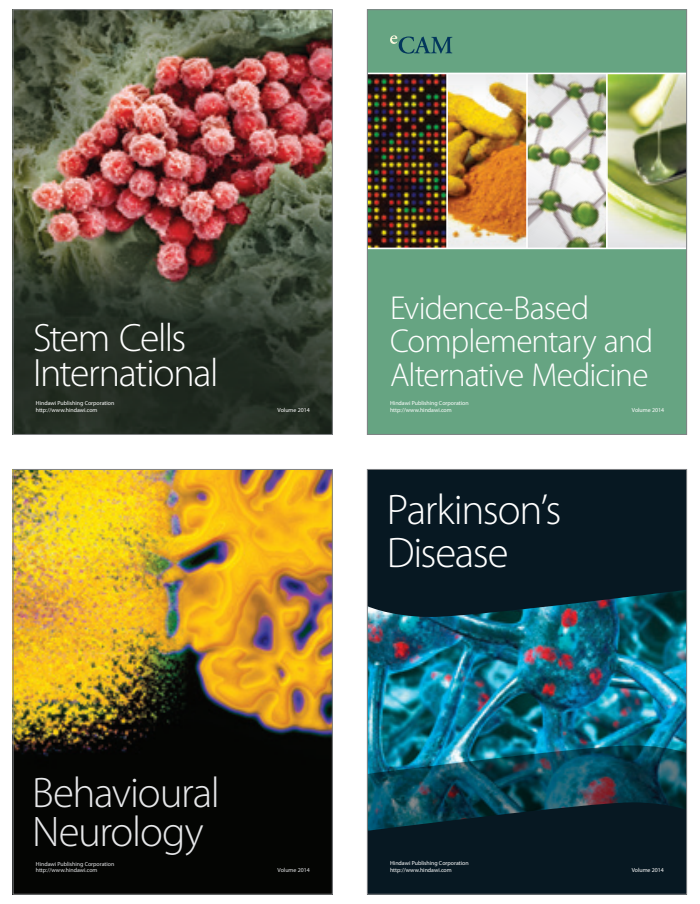
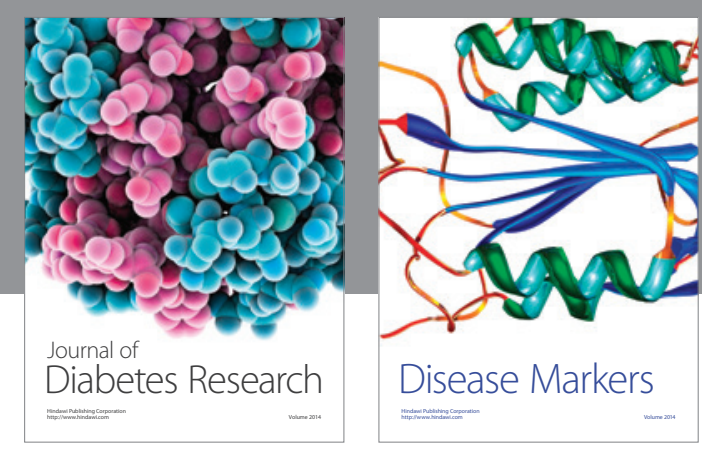

Disease Markers
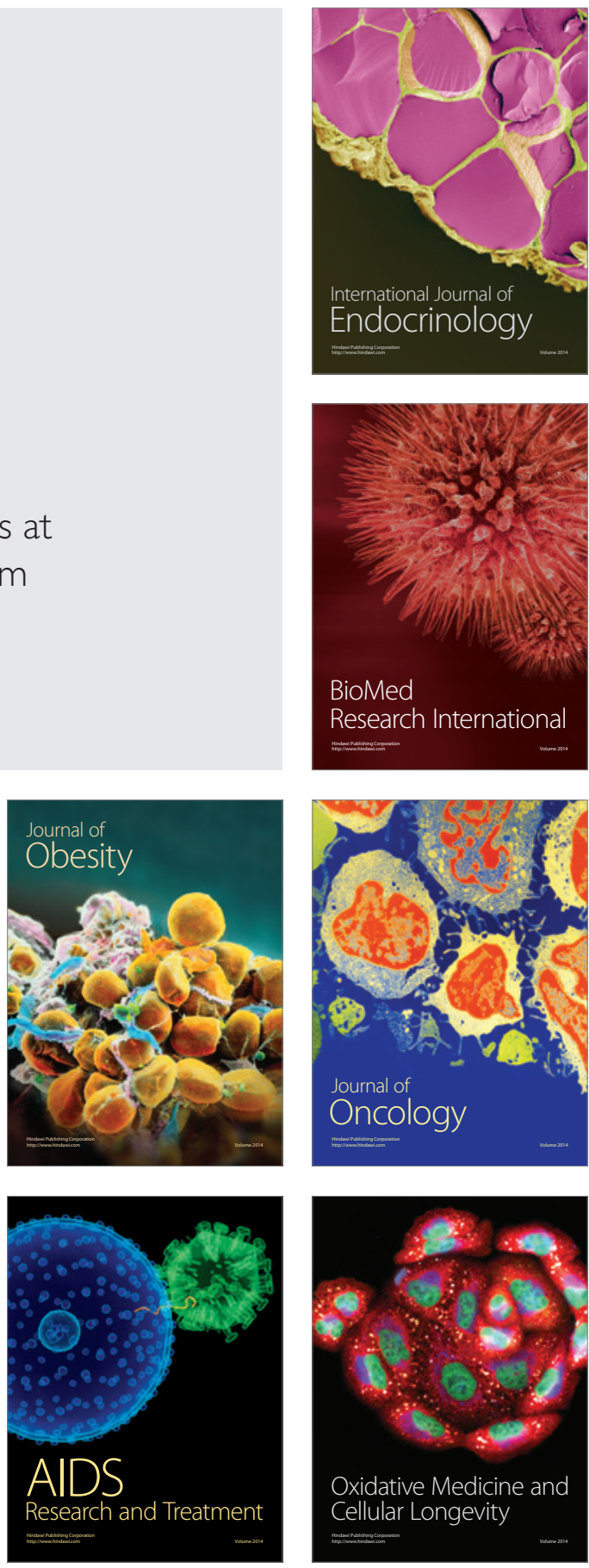